\title{
Ion Channels in Axon and Schwann Cell Membranes at Paranodes of Mammalian Myelinated Fibers Studied with Patch Clamp
}

\author{
G. F. Wilson ${ }^{1,2}$ and S. Y. Chiu ${ }^{1}$ \\ 'Department of Neurophysiology and 2Neuroscience Training Program, University of Wisconsin, Madison, Wisconsin 53706
}

While recent studies have established the presence of voltage-gated ion channels on Schwann cells in culture and on freshly isolated fibers from mature mammals, an important issue not yet explored is whether Schwann cell channels are regionally specialized. In the nodal region, the intimate association between the Schwann cell and its axon suggests that this is a likely site for functional specialization. Here, we examine whether there is a localized expression of channels in the Schwann cell paranodal regions, in a manner similar to that already shown for the nodal axon. Cell-attached and outside-out patch-clamp recordings were made from paranodal regions of rat myelinated sciatic nerve fibers where the myelin on both sides of the node was retracted by enzymatic treatment. Even though no myelin was visible on the surface of the retracted paranode, significant portions of this surface were found to stain positively with a marker (anti-galactocerebroside) for Schwann cell membranes, suggesting that part of the axon still was covered by glial membranes. Using Lucifer yellow in the recording pipettes, we observed that the dye diffused into either axons or Schwann cells when the membrane under the tip was ruptured. Using this as a criterion to identify membranes obtained from retracted paranodes, we found delayed and inwardly rectifying potassium channels on both axon- and Schwann-derived patches. However, sodium channels were detected only in axon patches. This is the first report that voltage-gated glial channels are present in immediate vicinity to axons of the PNS. This finding, coupled with earlier reports that functional channels are absent in soma of mature myelinating Schwann cells, suggests that ion channels in these cells are regionally specialized for functional interaction with axons.

The node of Ranvier is a narrow gap of axon along a myelinated fiber that generates currents for nerve impulses. This nodal region is one of the most congested sites of ion traffic in nerve signaling: the gap is a mere $0.5-1.0 \mu \mathrm{m}$ wide and contains the highest density of ion channels of all known excitable membranes. Clearly, a proper control of the microenvironment in

Received Mar. 21, 1990; revised May 21, 1990; accepted May 23, 1990.

We thank Craig Levinick for help in the EM studies and Carol Dizack and Terry Stewart for help in illustration and photography. This work was supported in part by Grants NS-23375 from the U.S. Public Health Service and RG-1839 from the U.S. National Multiple Sclerosis Society and by a Pew Scholar award in the Biomedical Sciences to S.Y.C.

Correspondence should be addressed to S. Y. Chiu, University of Wisconsin, Department of Neurophysiology, 283 Medical Sciences Building, 1300 University Avenue, Madison, WI 53706.

Copyright $\odot 1990$ Society for Neuroscience $0270-6474 / 90 / 103263-12 \$ 03.00 / 0$ the nodal region is crucial for normal nerve function. The complex axon-glia relation in this region suggests a glial role in modulating the nodal environment: the Schwann cell membrane differentiates into numerous finger-like microvilli that closely appose the nodal membrane, and the mitochondrial content in Schwann cells is highest near the paranode. Indeed, the complex, metabolically active paranodal apparatus has always been considered by morphologists to function as a whole unit in nodal physiology. Numerous hypotheses have been suggested for the control of the ionic balance at the node, including the attribution of buffering properties to the cation-binding substance present in the nodal gap (Landon and Langley, 1971), a direct shunting of currents from the nodal axon into Schwann cells (Brismar, 1983), and a role for Schwann cell paranodal pockets as a source and/or sink for Na ions needed for excitation (Ellisman et al., 1980).

An understanding of the properties of paranodal Schwann membrane is basic to assessing its role in influencing the nodal microenvironment. This region normally is inaccessible for electrophysiological studies of ion channels. Previous patch-clamp experiments on myelinating Schwann cells were restricted to the cell soma (Chiu, 1987, 1988). Interestingly, these studies have shown that channels are present only transiently during early development and disappear from the soma as the animal matures (Wilson and Chiu, 1990). However, the possibility of a regional specialization in ion channels in the paranodal region cannot be excluded.

In this study, patch-clamp experiments were performed in the paranodal region of mature rat myelinated fibers by retracting the myelin with enzymatic treatments. Using Lucifer yellowfilled pipettes to distinguish between the axon and the glial membrane, we found that both axon- and Schwann-derived patches can be obtained from retracted paranodes. As expected, axon patches possess channels similar to the described macroscopic currents in traditional gap-clamp studies (Stampfli and Hille, 1976). More important, Schwann patches also contain a variety of $K$ channels similar to those observed in the axon. This is the first evidence that voltage-gated channels are present in a glial region in immediate proximity to axons in a mature nerve fiber.

\section{Materials and Methods}

Cell preparation. Schwann cells from sciatic nerves of adult rats (SpragueDawley) were isolated acutely for morphological and patch-clamp studies by collagenase treatment $(0.3 \%$; Type I, Cooper Biomedical) for 1$2 \mathrm{hr}$ at $37^{\circ} \mathrm{C}$ as described previously (Chiu, 1987). Briefly, following incubation, nerve segments were teased apart gently and then sandwiched between 2 coverslips. Under Locke solution, the top coverslip was pushed aside carefully to expose dissociated fibers. Retracted paranodes (as in Fig. 2) appeared to be more abundant if, during teasing 
and spreading, tension was exerted along the nerve's longitudinal axis.

Electrophysiology. Electrophysiological experiments were performed using a Nikon Diaphot inverted microscope equipped with epifluorescent optics for viewing dye-stained cells. Patch-clamp studies were carried out as described previously (Wilson and Chiu, 1990). Briefly, using a List EPC-7 amplifier, recordings were made on myelinated nerve fibers 1-8 hr after isolation. The current output was low-pass filtered at $1-2$ $\mathrm{kHz}$ (8-pole Bessel, Frequency Device) and sampled every 100-300 $\mu$ sec. Pulse generation and data acquisition were performed with an SMS1000 microcomputer and an INDEC laboratory interface. Single-channel currents were recorded using cell-attached and outside-out configurations (Hamill et al., 1981). Formation of gigaseals on retracted paranodes appeared to be most easily accomplished when pipette resistances ranged from 10 to $30 \mathrm{M} \Omega$. Pipette junction potentials were nulled immediately prior to seal formation. Most membrane patches were held at either the cell resting potential (cell-attached) or $-75 \mathrm{mV}$ (outside-out).

In voltage-ramp experiments, the membrane potential was ramped linearly between the 2 indicated potentials at a speed of $0.83 \mathrm{~V} / \mathrm{sec}$, and the response was sampled every $300 \mu \mathrm{sec}$, as described previously (Wilson and Chiu, 1990). Typically, 20 individual ramp responses were averaged for each ensemble. Leakage currents were subtracted using a leakage template generated either by linear extrapolation between observed closed segments within a single ramp trace or by using traces with no channel openings (Wilson and Chiu, 1990). Current-voltage ( $I$ $V)$ relations for open channels were obtained first by averaging open segments selected from the current series, then subtracting the leakage from the averaged currents using leakage templates generated from averaged closed segments. The open-channel probability $\left(p_{0}\right)$ was determined by dividing the average current by the open-channel current.

In voltage-step experiments, the membrane patch was stepped to various potentials from a holding potential of $-75 \mathrm{mV}$. Test pulses were preceded by a prepulse to $-120 \mathrm{mV}$. Currents were sampled at $100 \mu \mathrm{sec}$, unless otherwise indicated, and capacitative and linear leakage currents were subtracted from all records prior to analysis and display. Kinetic analysis was performed on ensemble currents. Activation of peak sodium conductance was determined from the $I-V$ relations by dividing the peak currents by $\left(E-E_{\mathrm{Na}}\right)$, then normalizing by the maximum conductance at $-35 \mathrm{mV}$. Steady-state sodium current inactivation was determined by measuring the peak current at $-5 \mathrm{mV}$ as the prepulse potential was varied. Prepulse durations of $100 \mathrm{msec}$ were used. The inactivation time constant for sodium current, $\tau_{h}$, was determined from semilog plots of the initial decaying phase of the current. For potassium current, $\tau_{n}$ was determined by fitting the rise phase of the current with the equation $I=A\left(1-\exp \left[-\left(t-t_{D}\right) / \tau_{n}\right]\right)^{4}$, where $A$ is a constant, and $t_{D}$ is a constant such that $I=0$ for $0<t<t_{D}$.

Solutions. Unless otherwise mentioned, the bath solutions used in the present experiments were essentially $\mathrm{Ca}^{2+}$ free to minimize the possibility of fusion between axonal and Schwann membranes. However, the presence or absence of $\mathrm{Ca}^{2+}$ did not appear to influence the likelihood of obtaining either Schwann- or axon-derived patches. Cells normally were bathed in Locke solution containing $154 \mathrm{~mm} \mathrm{NaCl}, 5.6 \mathrm{~mm} \mathrm{KCl}$, $0 \mathrm{~mm} \mathrm{CaCl}, 2 \mathrm{~mm}$ EGTA, and $10 \mathrm{~mm}$ morpholinopropionyl sulfonate buffer ( $\mathrm{pH}, 7.4)$. In some experiments, potassium was substituted for sodium, resulting in a final potassium concentration of $160 \mathrm{~mm}$. In cellattached and excised outside-out recordings examining primarily potassium currents, the pipettes were filled with a $140-\mathrm{mm} \mathrm{KCl}$ solution that contained $140 \mathrm{~mm} \mathrm{KCl}, 1 \mathrm{~mm} \mathrm{CaCl}, 2 \mathrm{~mm} \mathrm{MgCl}, 10 \mathrm{~mm}$ EGTA, $10 \mathrm{~mm}$ Hepes buffer; the $\mathrm{pH}$ of the solution was brought to 7.2 by addition of $27 \mathrm{~mm} \mathrm{NaOH}$. In sodium current experiments, pipette solutions contained: $70 \mathrm{~mm} \mathrm{CsCl,} 70 \mathrm{~mm}$ tetraethylammonium chloride (TEACl), $1 \mathrm{~mm} \mathrm{CaCl}, 2 \mathrm{~mm} \mathrm{MgCl}_{2}, 10 \mathrm{~mm}$ EGTA, and $10 \mathrm{~mm}$ Hepes buffer (pH, 7.2).

Immunofluorescent labeling. Retracted paranodes were labeled with a monoclonal antibody to galactocerebroside (Gal-C), a surface marker for Schwann cell membranes, which was generously provided by $B$. Ranscht (Ranscht et al., 1982). Briefly, nerve fibers, prepared as for patch-clamp experiments, were preincubated in Locke solution containing $10 \%$ calf serum (blocking solution) for $30 \mathrm{~min}$, then incubated in Gal-C (1:200, in blocking solution) for 30-60 min. After several washes in plain Locke solution, cells were incubated in fluoresceinconjugated anti-mouse IgG3 (1:100 in blocking solution; Organon Teknika-Cappel) for $1 \mathrm{hr}$, then washed prior to viewing.

Lucifer yellow staining. Lucifer yellow CH (dilithium salt, Sigma) was prepared at $1 \%$ concentration using either of the above-listed pipette solutions. The precipitatc was filtered out (using $0.2-\mu \mathrm{m}$ frtters) immediately prior to filling pipettes; the final concentration of Lucifer yellow obviously was sufficient to mark cells. Surprisingly, no precipitation occurred when Lucifer yellow was prepared in solution containing TEACl. Lucifer yellow was injected into retracted paranodes by diffusion. Typically, paranodes were maintained in whole-cell recording mode for 3-7 min after the initial disruption of the membrane to allow sufficient time for diffusion through axons or the many myelin layers of Schwann cells.

Cells were stained with Lucifer yellow immediately following cellattached recordings or immediately prior to outside-out recordings using the same pipette as for the recordings. Only responses from cell-attached or outside-out patches where Lucifer yellow clearly marked either the axon or the Schwann cell have been included in this report. This represented $20 \%$ of the attempted Lucifer ycllow injections; in the remaining $80 \%$, either (1) there was no diffusion of the dye out of the pipette; (2) dye was limited to a small area on the paranode surface, perhaps a membrane fragment or vesicle; or (3) dye was confined to one side of the node but was too dim to identify the other characteristics typical of the 2 categories (see Fig. 4). Lucifer yellow never was seen to diffuse to both Schwann cells and axons.

Electron microscopy. Sciatic nerves used for morphologic examination of retracted paranodes were prepared as for patch-clamp experiments. Generally, coverslips with well-spread nerve fibers were fixed with $4 \%$ glutaraldehyde in Locke solution for $1 \mathrm{hr}$ at room temperature. After fixation, nerves were rinsed in Locke solution, postfixed in $2 \%$ $\mathrm{OsO}_{4}$, dehydrated, and embedded in Durcupan. Embedded Schwann cells with retracted paranodes were selected for longitudinal sectioning.

Whenever possible, mean values \pm the standard crror of the means are given. All experiments were done at a room temperature of around $25^{\circ} \mathrm{C}$.

\section{Results}

With potassium in the pipettes and sodium as the major cation in the bath, whole-cell recordings made at the soma of adult myelinating Schwann cells usually show no sign of voltage-dependent currents (Chiu, 1987). Indeed, cell-attached recordings at the cell soma of adult myelinating cells show no potassium channel activities (Wilson and Chiu, 1990). However, when whole-cell recordings were made from Schwann cells bathed in $160 \mathrm{~mm}$ potassium Locke solution, an inwardly rectifying current was sometimes observed for small-diameter fibers. A typical example is shown in Figure 1, left. A significant portion of this current was reduced by external $\mathrm{Cs}^{+}$(Fig. 1, right), suggesting that the observed current is similar to the inwardly rectifying potassium currents seen transiently during development (Wilson and Chiu, 1990). Because these channels disappear from the soma during the initial phase of myelin formation (Wilson and Chiu, 1990), the whole-cell currents observed in Figure 1 may be extrasomal in origin. Indecd, the block produced by bath-applied $\mathrm{Cs}^{+}$took significantly longer (typically, 3-15 min) than would be expected if channels were freely exposed. One possibility is that channels are wrapped within the myelin or located at the distant paranodal processes. It therefore seems unlikely that the currents shown in Figure 1 are under adequate space clamp. In order to study the currents under strict voltageclamp conditions, the experiments that follow were performed using single-channel recordings at sites away from the soma, namely, the paranode.

\section{Membrane identification at the paranode}

In our early experiments searching for channels on normal adult paranodes, channels were not detected (approximately 30 cellattached patches with $\mathrm{KCl}$ in the pipette), suggesting that either functional channels are absent from the surface membrane of myelinating Schwann cells or that the density of active channcls is fairly low. In contrast, channels often were encountered in 
$0 \mathrm{~min}$

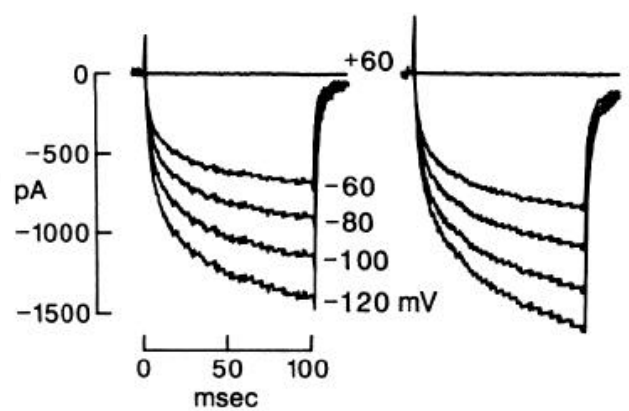

Figure 1. Whole-cell recordings from soma of myelinating adult Schwann cell. The pulse protocol used here was similar to that used in whole-cell studies of inward rectifiers in glia (Barres et al., 1988). Briefly, from a holding potential of $+60 \mathrm{mV}$, the membrane was stepped to $+60,-60,-80,-100$, and $-120 \mathrm{mV}$, respectively (the lowest current trace corresponds to $-120 \mathrm{mV}$ ). Leakage currents have been subtracted using currents elicited by stepping the membrane from the holding potential to $+85 \mathrm{mV}$. The cell was initially bathed in isotonic $\mathrm{K}$ ( 160 mM K Locke solution; see Materials and Methods). The indicated times denote times following bath application of a Locke solution containing $80 \mathrm{~mm} \mathrm{CsCl}$ and $80 \mathrm{~mm} \mathrm{KCl}$. The current reduction took a long time to occur (15 min, right). Similar results were obtained when the bath solutions were switched from $140 \mathrm{~mm} \mathrm{KCl}$ and $20 \mathrm{~mm}$ tetramethylammonium chloride (TMA; control) to $140 \mathrm{mM} \mathrm{KCl}$ and $20 \mathrm{mM} \mathrm{CsCl}$. This suggests that the current reduction is due to channel block by $\mathrm{Cs}^{+}$, as noted for other inward rectifiers, as opposed to a decrease in conductance resulting from a decreased $\mathrm{K}^{+}$concentration. Pipettes contained $140 \mathrm{~mm} \mathrm{KCl}$ (see Materials and Methods).

patch-clamp recordings made from paranodes where a major portion of the myelin sheath appeared retracted. Figure 2, $A$ and $B$, presents 2 examples of these retracted paranodes. The length of exposed membrane varied considerably between cells, and retracted paranodes could appear straight (Fig. $2 A$ ) or widened on either side of the presumed node (Fig. $2 B$ ). While the newly exposed membrane appears devoid of myelin, it is pos- sible that a thin Schwann membrane still may cover the axon Indeed, similar widened nodes of Ranvier, which retain a thin Schwann layer, have been observed after myelin retraction following treatment with low calcium in culture (Blank et al., 1974). Figure $2 C$ shows the retracted paranode in Figure $2 B$ following exposure to an antibody to Gal-C, which selectively recognizes Schwann cell membranes. In most cases, both the myelin and the surface of retracted paranodes proved to be Gal-C positive. The nodal gap was never labeled.

One likely explanation for the Gal-C labeling pattern is that fragments of Schwann cell membrane are left behind as the axon's paranodal membrane is exposed. Figure 3 shows longitudinal electron-microscopic sections of sciatic nerve fibers with retracted paranodes. Although the presumed nodal membrane appears devoid of fragments (Fig. 3A), membrane vesicles are scattered along the axon's paranodal region, which often appears as a widening of the axon. These vesicles are similar to those observed within the paranodal myelin loops (shown at higher magnification in Fig. $3 B$ ) and, if they originate from the Schwann cell, would appear to account for the Gal-C staining of this region.

The above results suggest that the membrane on the surface of retracted paranodes might originate from either Schwann cells or axons and, further, that it may be difficult to distinguish between the 2 membranes during patch recordings. To circumvent this problem, $1 \%$ Lucifer yellow was injected by diffusion from patch pipettes applied to the retracted paranode region (Fig. 4A, arrowhead). Primarily, 2 staining patterns were observed. In the first (Fig. $4 B$, left), dye spread to both sides of the node, often extended beyond the next node, and was contained within a band narrower than the width of the myelin sheath. This staining pattern was assumed to be a result of patching the axonal membrane. In the second type (Fig. $4 B$, right), dye never crossed nodal boundaries, extended through the entire width of the myelin sheath on only 1 of the 2 internodes flanking the node, appeared most fluorescent along the
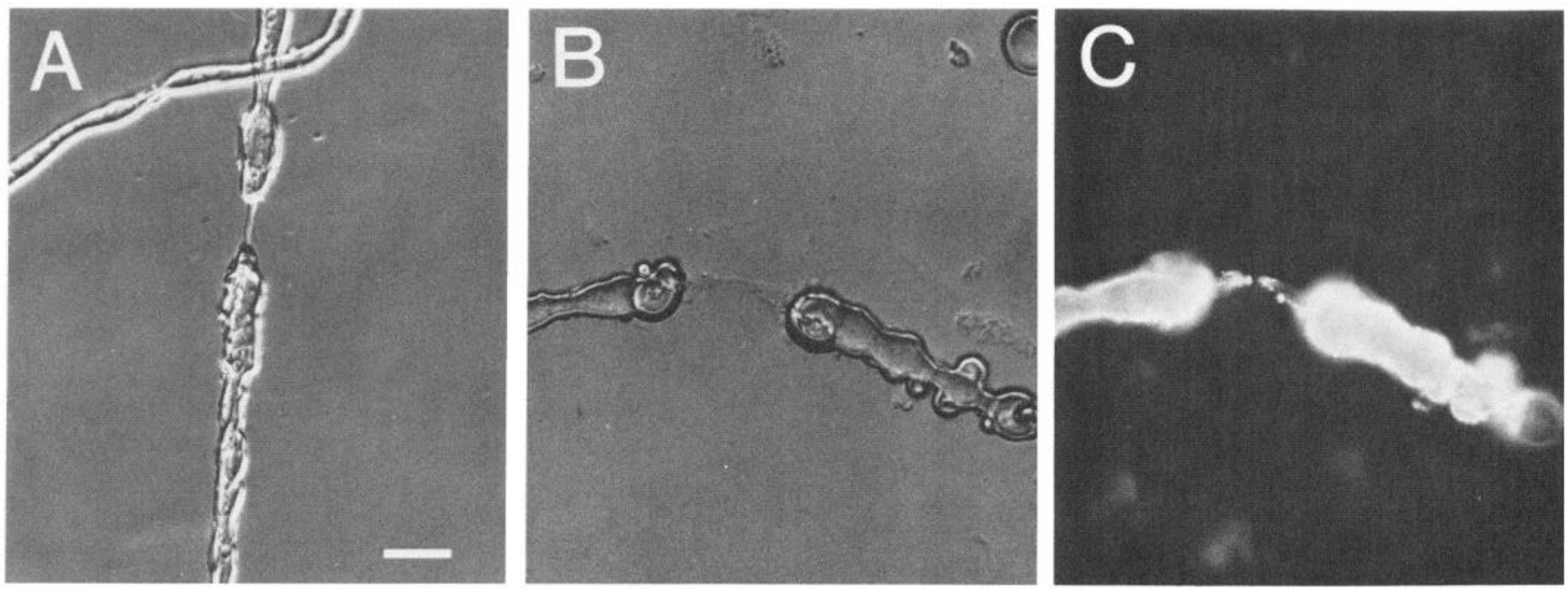

Figure 2. Retracted paranodes in acutely dissociated adult rat sciatic nerve fibers. A, Example of a retracted paranode with a straight segment between myelin borders. $B$, Example of a retracted paranode where the axon appeared to widen as it approached the myelin sheath. $C$, Same fiber as shown in $B$ following immunohistochemical labeling with a monoclonal antibody to Gal-C and fluorescein-conjugated IgG3. Note that label was found on the outermost surface of the internodes on both sides, as well as on a major portion of the rectracted paranode. The nodal gap, in contrast, was not labeled. Scale bar in $A$ represents $20 \mu \mathrm{m}$ and applies to $A-C$. Retracted paranodes were obtained by enzymatic treatments, as described in Materials and Methods. 
Figure 3. Electron micrographs of longitudinally sectioned retracted paranodes. Note the membrane vesicles along both sides of the presumed former paranodal region $(A)$; the bulging segment near the center may correspond to the nodal region. Scale bar, 3 $\mu \mathrm{m}$. $B$, Higher magnification at the myelin border from a different fiber. Scale bar, $1 \mu \mathrm{m}$.
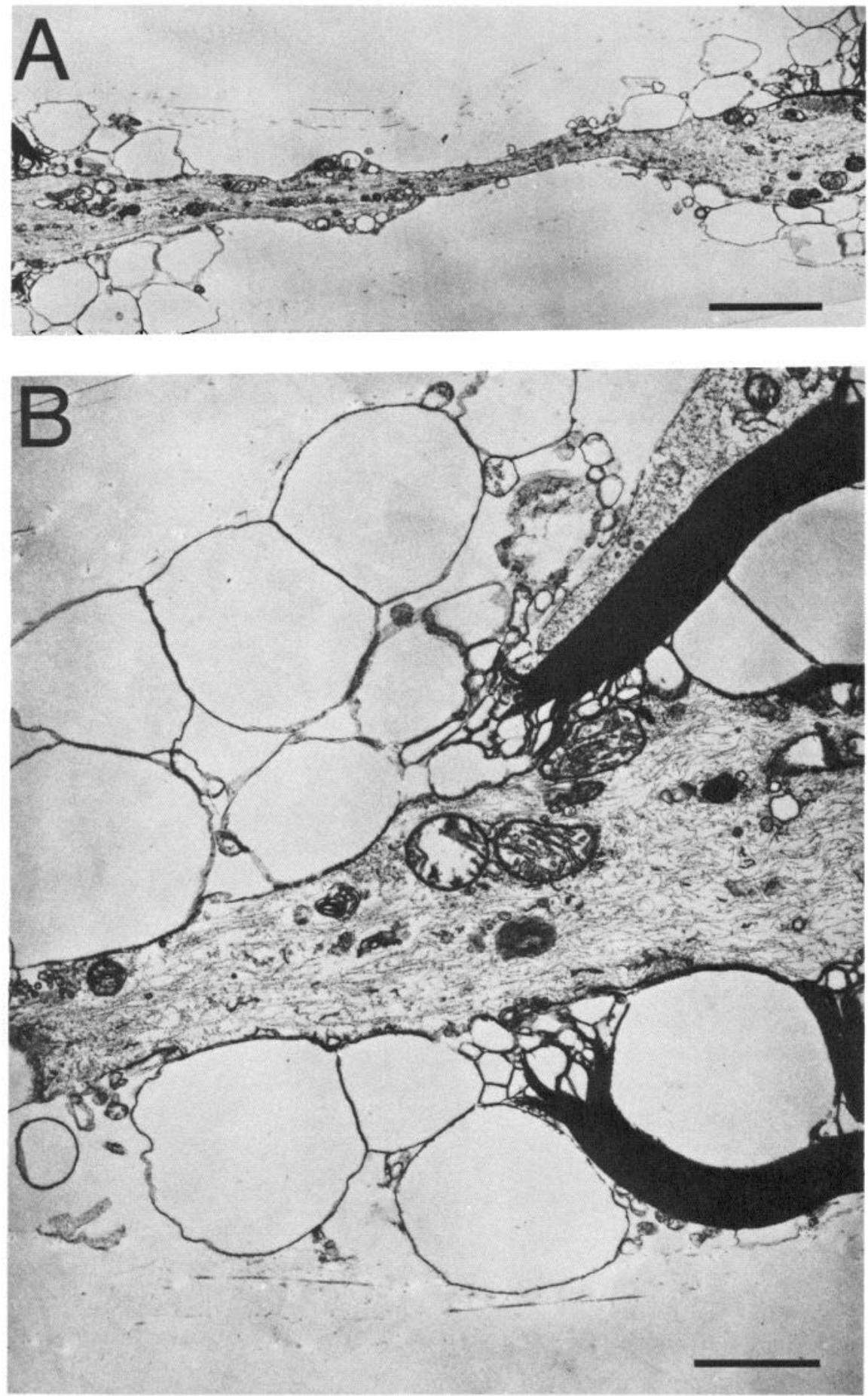

myelin's outer perimeter, and indeed, often extended into the Schwann cell soma. This second type of staining pattern was assumed to be a result of patching the membrane that belonged to the ensheathing Schwann cell. Because $45 \%$ of the 98 successful injections marked Schwann cells, these results suggest there is an approximately equal probability of recording from axonal and Schwann cell membrane when applying pipettes to retracted paranodes. Furthermore, it appears that at least some membrane "fragments" remain continuous with the Schwann cell proper (and, in fact, may be paranodal loops, albeit a bit distorted).
Of obvious interest is whether Schwann and axonal patches differ in channel properties. In the experiments reported here, retracted paranodes were approached with pipettes containing $1 \%$ Lucifer yellow in intracellular recording solution (see Materials and Methods). In all cases, the patch pipette was placed midway between the presumed node and the myelin border. Only responses from cell-attached or outside-out patches where Lucifer yellow clearly marked either the axon or the Schwann cell have been included in this report (see Materials and Methods). Unless otherwise noted, experiments were performed in essentially $\mathrm{Ca}^{2+}$-free solutions to minimize the possibility of 


\section{PARANODE}

\section{Axon}

A

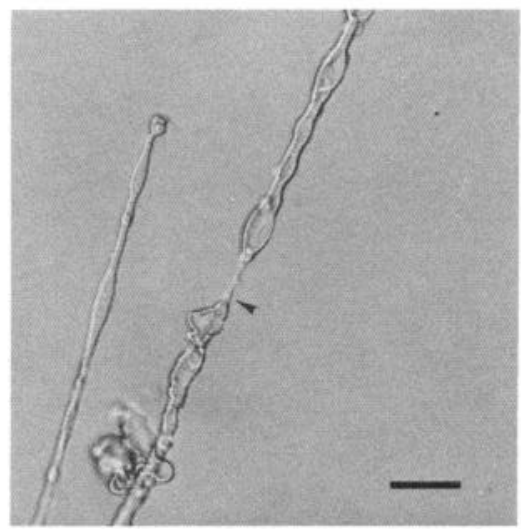

B
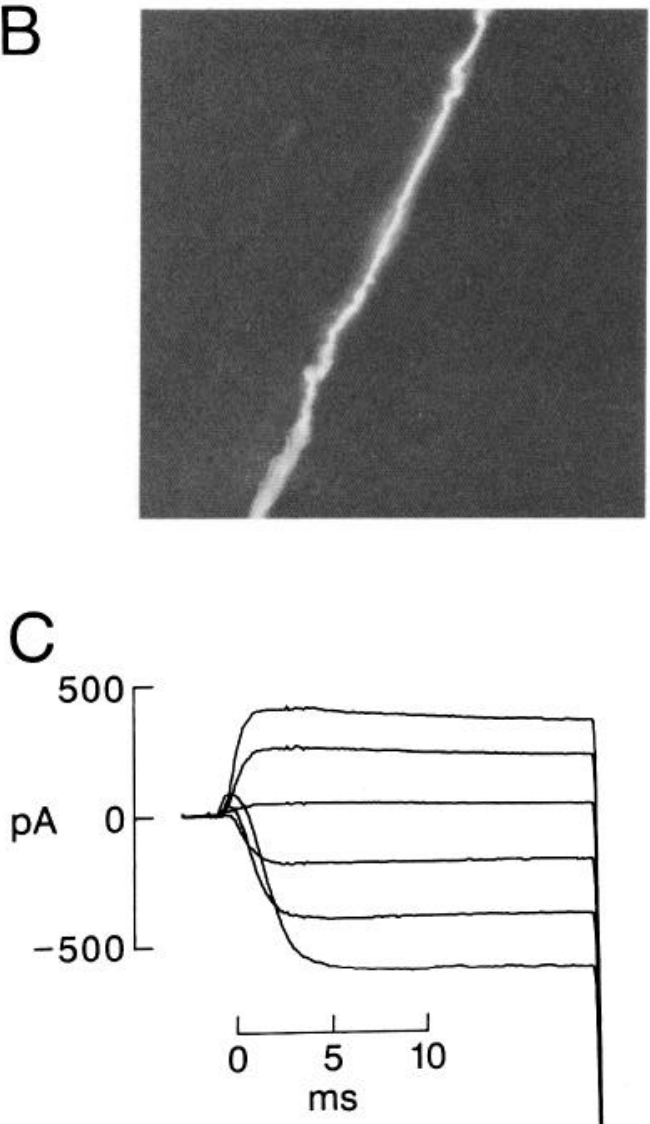

Schwann
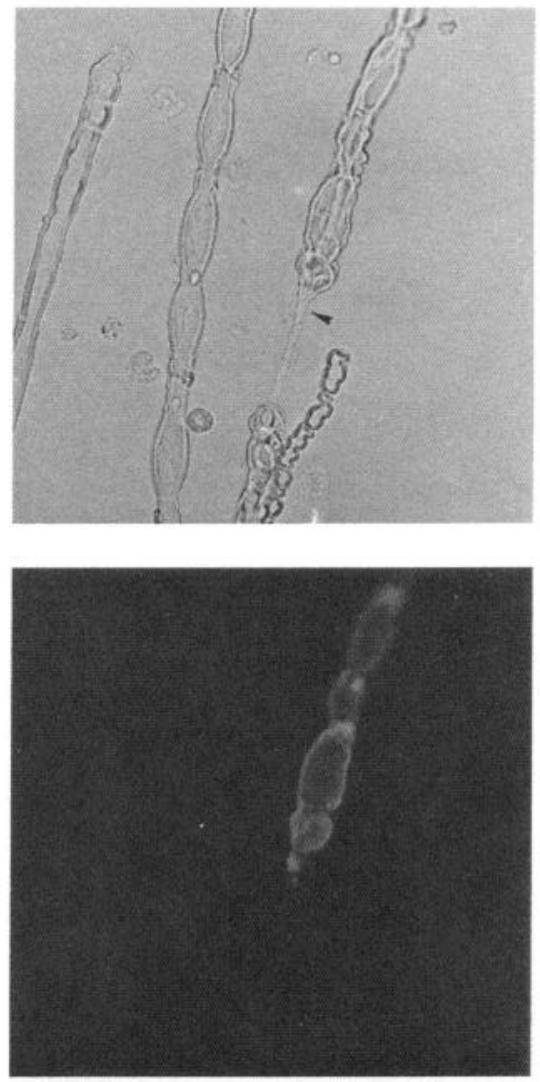

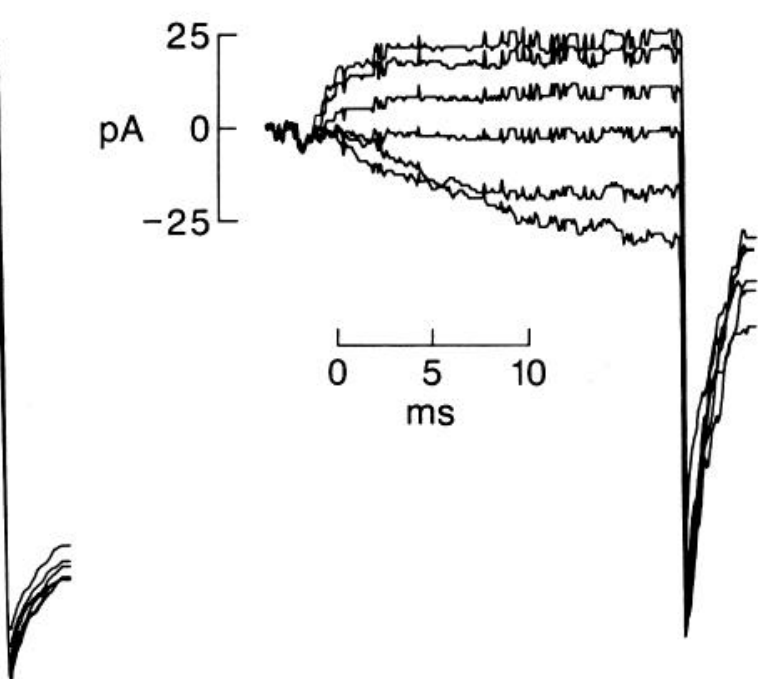

Figure 4. Membrane identification using Lucifer yellow. A, Two examples of retracted paranodes examined with Lucifer-containing recording pipettes. $B$, Same fibers as shown in $A$ following Lucifer yellow injection at the indicated locations $(A$, arrowheads), as viewed with epifluorescence optics. Patches originating from paranodes stained as shown on the left were classified as axon derived, while patches originating from paranodes stained as shown on the right were classified as Schwann derived. Scale bar in $A$ represents $20 \mu \mathrm{m}$ and applies to $A$ and $B$. $C$, Recordings from 2 outside-out patches originating from axonal (left) and Schwann cell (right) paranodal membranes. Inward current is plotted downwards. The patch shown on the left was stepped from -10 to $+60 \mathrm{mV}$ in $20-\mathrm{mV}$ increments from a holding potential of $-100 \mathrm{mV}$; the patch on the right was stepped from -5 to $+65 \mathrm{mV}$ in $20-\mathrm{mV}$ increments from a holding potential of $-75 \mathrm{mV}$. In both cases, the bath contained $160 \mathrm{~mm} \mathrm{KCl}$ Locke solution, and pipettes contained $140 \mathrm{~mm} \mathrm{KCl}$ (see Materials and Methods). Data were filtered at $1 \mathrm{kHz}$ and sampled every $100 \mu$ sec. 

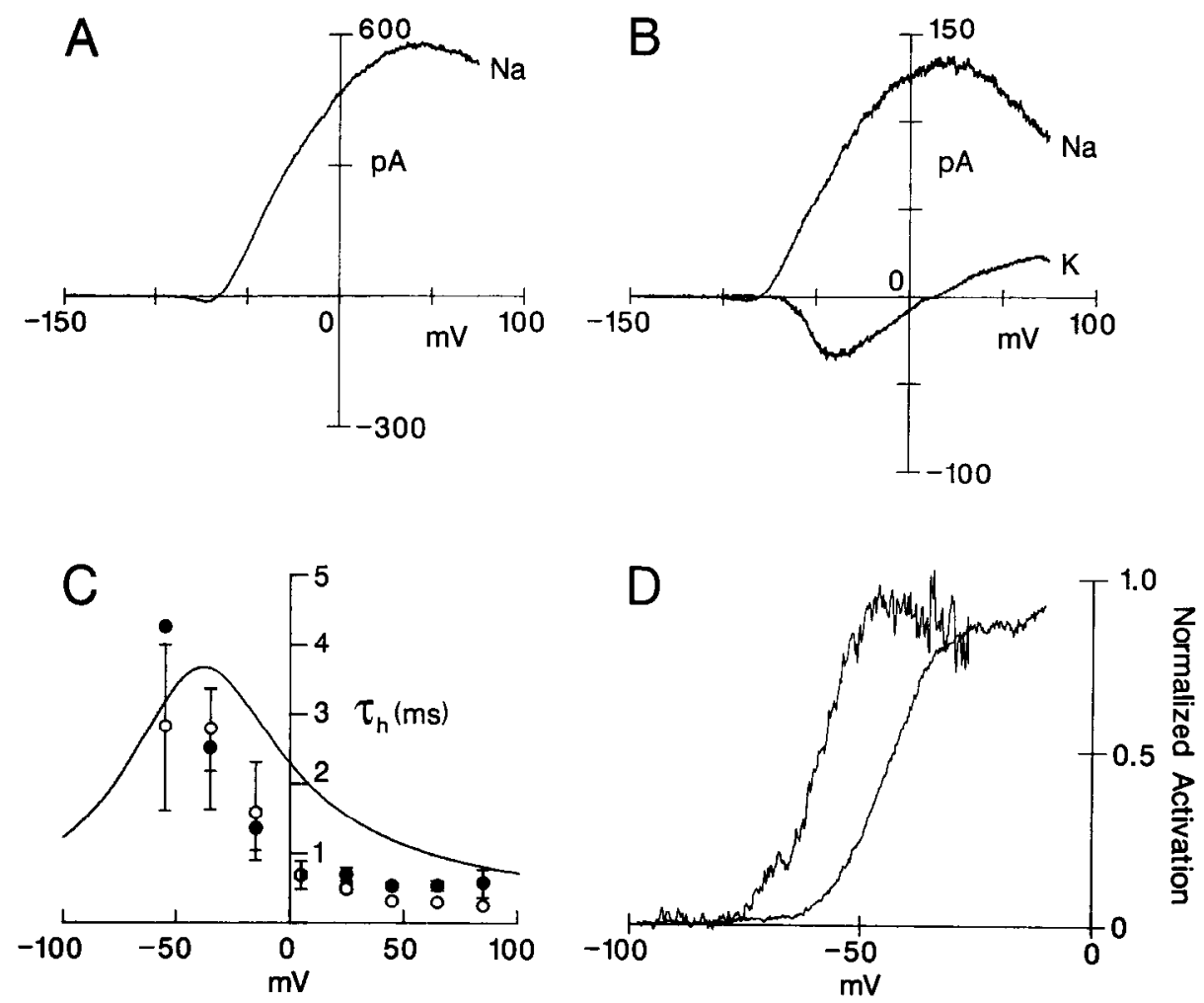

Figure 5. Delayed rectifying potassium currents in axon- and Schwann-derived outside-out paranodal patches. $A$, Axon-derived patch. Currents are in response to a voltage ramp. The bath contained $156 \mathrm{~mm} \mathrm{NaCl}$ Locke solution. $B$, Schwann-derived patches. For the first patch (lop trace), the bath contained $156 \mathrm{mM} \mathrm{NaCl}$ Locke solution, while for the second patch (bottom trace), the bath contained $160 \mathrm{~mm} \mathrm{KCl}$ Locke solution. In all cases, the pipette contained $140 \mathrm{mM} \mathrm{KCl}$. In both $A$ and $B$, each trace represents the average of 10 individual responses to a linear voltage ramp from -150 to $+100 \mathrm{mV}$. Currents were filtered at $1 \mathrm{kHz}$ and sampled every $300 \mu \mathrm{sec} . \mathrm{C}$, voltage dependence of the time constant of activation $\left(\tau_{n}\right)$ for delayed-rectifying potassium currents for axons (open circles, $n=5$ ) and Schwanns (solid circles, $n=3$ ) studied with voltage steps (see Materials and Methods). Data were pooled from 2 different patch configurations (cell-attached and outside-out); in cell-attached patches, the bath contained $160 \mathrm{mM} \mathrm{KCl}$, and absolute potentials were calibrated assuming a resting potential of 0 . The solid curve represents theoretical frog $\tau_{n}$ calculated using the equation $\tau_{n}=1 /\left[\alpha_{n}(V)+\beta_{n}(V)\right]$, with $\alpha_{n}(V)$ and $\beta_{n}(V)$ taken from Table 1 of Schwarz and Eikhof $(1987)$. $D$, Normalized voltage dependence of conductance for the delayed rectifiers in Schwann cells (left curve, $n=2$ ) and axons (right curve, $n=4)$. Data were obtained from cell-attached patches with $160 \mathrm{mM} \mathrm{KCl}$ Locke solution in the bath; pipettes contained $140 \mathrm{mM} \mathrm{KCl}$. Conductance, $G$, was calculated from the ramp current, $I$, according to the equation $G=I /\left(E-E_{K}\right)$, where $E_{K}$ is the reversal potential determined from ramp $I$ - $V$ currents (see lower trace in $B$ ). Absolute potentials were calibrated assuming a resting potential of $0 \mathrm{mV}$ in all cases.

fusion between axonal and Schwann cell membranes. In no case was Lucifer yellow seen to diffuse into both axons and Schwann cells.

\section{Delayed-rectifying $K$ currents}

Currents resembling delayed rectifiers in excitable membranes were observed in $100 \%$ and $50 \%$ of the 15 axon- and 21 Schwannderived patches, respectively. Figure $4 C$ shows currents observed in outside-out patches derived from axon (left) and Schwann (right) membranes under approximately symmetrical $\mathrm{K}$ conditions. Currents were elicited by a series of voltage steps ranging from -10 to $65 \mathrm{mV}$. Both currents activated more rapidly with increasing depolarization, reversed around $0 \mathrm{mV}$, and inactivated only minimally (by about $20 \pm 5 \%, N=6$; measured at the end of a 100 -msec depolarization that elicited the peak outward current, ranging from +65 to $+105 \mathrm{mV}$ ). Even though no quantitative comparisons were made, current magnitudes appeared to be on the average 10 times smaller in Schwann-derived patches.

When $\mathrm{Na}^{+}$was the major cation outside the membrane, only outward currents were observed. Figure 5, $A$ and $B$, presents typical $I-V$ relationships obtained from axon- $(A)$ and Schwann- derived $(B)$ outside-out patches in response to linear voltage ramps from -150 to $+100 \mathrm{mV}$ with normal $(154 \mathrm{mM}) \mathrm{Na}^{+}$in the bath. Each trace represents the average of 20 individual responses. For comparison, the lower trace in Figure $5 B$ shows the corresponding relation with $160 \mathrm{mM} \mathrm{K}^{+}$in the bath for a different Schwann-derived patch. In the few cases where discrete channel activity could be discerned, the slope conductance $(\gamma)$ for this channel was estimated as 13-14 pS, in agreement with previous measurements for delayed rectifiers in frog nodes (Conti et al., 1984) and Schwann cells (Shrager et al., 1985; Wilson and Chiu, 1990).

A kinetic analysis of potassium channel activation using macroscopic currents is shown in Figure 5, $C$ and $D$. The time constant of activation for potassium currents, $\tau_{n}$, appears to be similar in axon- (open circles) and Schwann-derived (solid circles) patches (Fig. $5 \mathrm{C}$ ). The solid curve shows theoretical voltage dependence of $\tau_{n}$ obtained for the frog node; in comparison, the voltage dependence of the present $\tau_{n}$ appears to be shifted by about $20 \mathrm{mV}$ in the hyperpolarizing direction. This is presumably due to the absence of external calcium in this study.

Figure $5 D$ presents the average normalized activation curve for conductance obtained from $I-V$ relations for Schwann- $(n=$ 

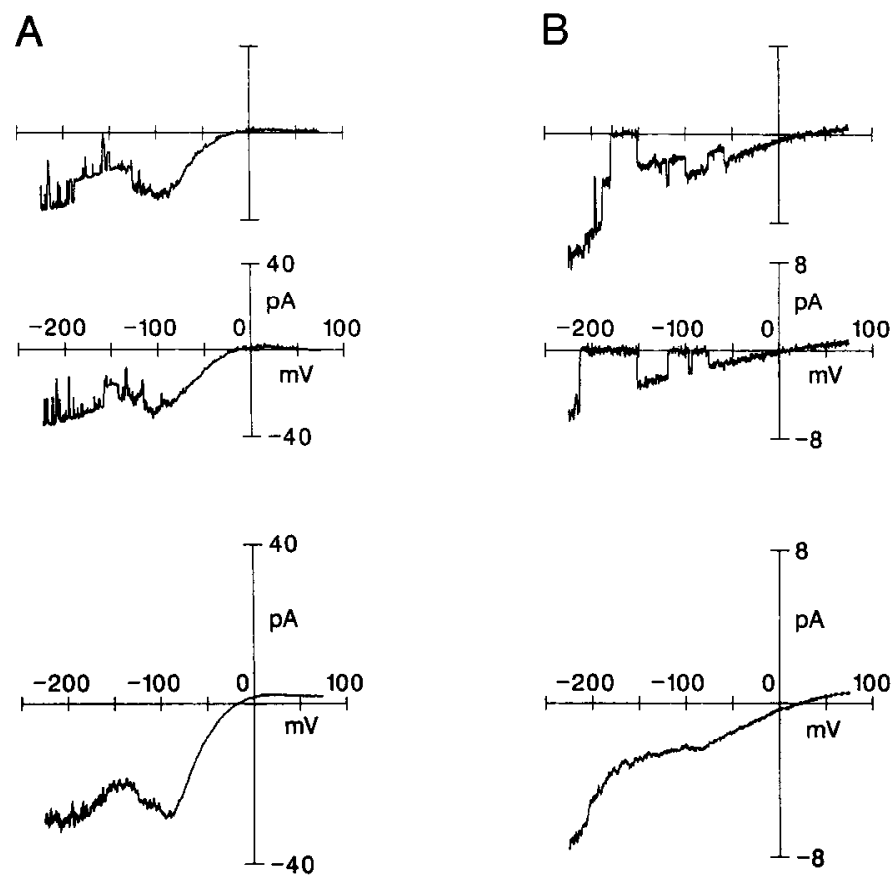

Figure 6. Inwardly rectifying currents in axon $(A)$ and Schwann $(B)$ patches. The top 2 traces are individual records, and the bottom trace is the ensemble average of 10-20 records. $A$, Cell-attached patch with $156 \mathrm{~mm} \mathrm{NaCl}$ Locke solution in the bath. The absolute potentials shown have been calculated assuming a resting potential of $-75 \mathrm{mV} . B$, Outside-out patch with $160 \mathrm{~mm} \mathrm{KCl}$ Locke solution in the bath. In both $A$ and $B$, pipettes contained $140 \mathrm{~mm} \mathrm{KCl}$. Data were filtered at $1 \mathrm{kHz}$ and sampled every $300 \mu \mathrm{sec}$.

2) and axon-derived $(n=4)$ cell-attached patches with $160 \mathrm{mM}$ $\mathrm{K}^{+}$in the bath. A comparison of the 2 curves suggests that Schwann channels activate at more hyperpolarized potentials (about $15 \mathrm{mV}$ more negative) when compared with axon channels.

Finally, with pipettes containing $140 \mathrm{~mm} \mathrm{CsCl}$, a significant portion of outward current remained in both axon- and Schwannderived outside-out patches (data not shown). However, switching to pipettes containing $70 \mathrm{~mm} \mathrm{CsCl}$ and $70 \mathrm{~mm}$ TEACl eliminated outward currents completely; one possible interpretation is that axonal and Schwann paranodal membranes may contain 2 populations of delayed-rectifying potassium channels distinguishable by their $\mathrm{Cs}^{+}$sensitivity.

\section{Inward rectifiers}

With $\mathrm{K}^{+}$as the major cation on the outside of the membrane, inward current activity could be observed over the hyperpolarizing potential range in half of both axon- $(N=10)$ and Schwannderived $(N=9)$ patches. Figure 6 shows current responses from an axon-derived cell-attached patch (left column) and a Schwannderived outside-out patch (right column). The currents were generated by a linear voltage ramp; the top 2 traces in each column are the individual responses, and the bottom-most trace is the ensemble average of 20 responses. Currents were clearly inwardly rectifying (with an estimated reversal potential around $0 \mathrm{mV}$ ) and activated over a potential range distinct from the activation range for delayed rectifiers. The axon channels (Fig. 6 , left) may correspond to the inward rectifiers recently described in rat spinal root myelinated axons (Baker et al., 1987).

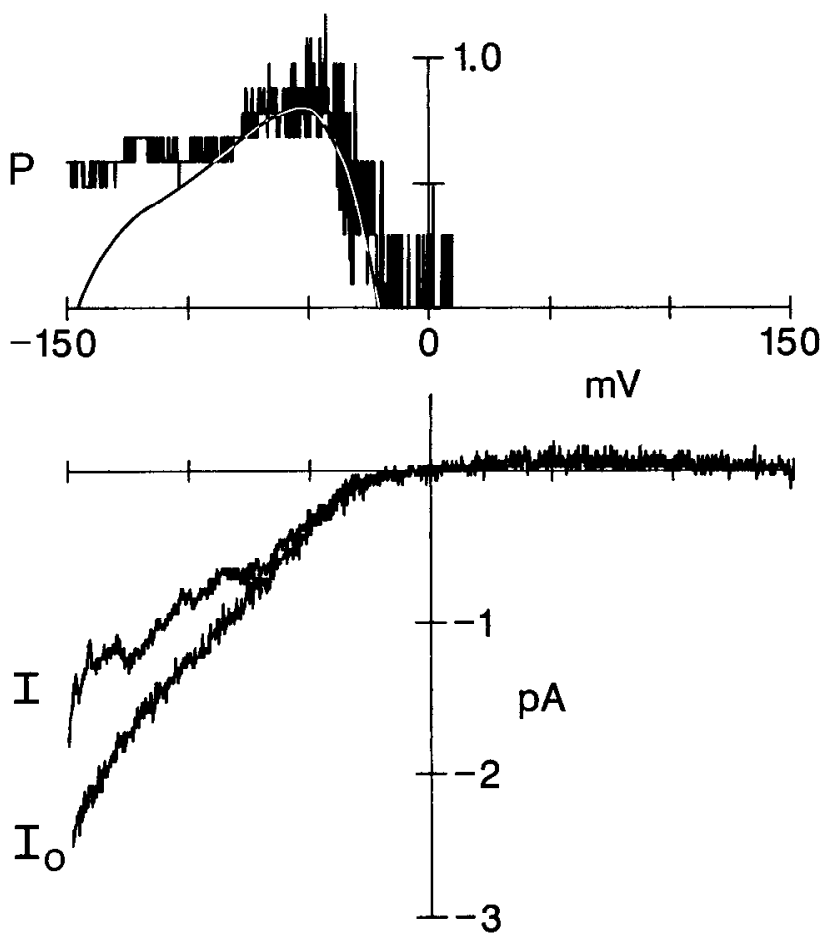

Figure 7. Voltage dependence of open-channel probability for inward rectifiers in Schwann-derived patches. The upper trace $(P)$ shows average open-channel probability from 3 cell-attached patches. $P$ was obtained by dividing the ensemble current $(I)$ by the open-channel current $\left(I_{o}\right)$. Both $I$ and $I_{o}$ represent the average from the 3 patches. $I_{o}$ was determined by averaging open segments selected from a series of individual current traces elicited by the same ramp protocol, then subtracting the leak current from the averaged open-channel current using leak templates. Leak templates were obtained by similarly averaging closed segments. The smooth curve superimposed on the $P$ data represents the corresponding open-channel probability for inwardly rectifying potassium channels in soma of developing Schwann cells (taken from Fig. 8 of Wilson and Chiu, 1990). Pipettes contained $140 \mathrm{mM} \mathrm{KCl}$; the bath contained $160 \mathrm{mM} \mathrm{KCl}$ Locke solution with $2.2 \mathrm{mM} \mathrm{Ca}^{2+}$.

In many patches, multiple conductance levels (presumably reflecting multiple channels) were observed. Figure 7 presents the average open-channel $I-V$ relationship $\left(I_{o}\right)$ for 3 Schwannderived cell-attached patches containing only 1 active channel. The average slope conductance for these channels was $25 \mathrm{pS}$, as measured between -150 and $-50 \mathrm{mV}$. This is smaller than the $35 \mathrm{pS}$ reported for inward rectifiers in developing Schwann cells (Wilson and Chiu, 1990). However, in that study, the singlechannel conductance was determined over a more hyperpolarized potential range (about -230 to $-160 \mathrm{mV}$ ). Finally, the open-channel probability $(P)$, obtained by dividing the average ramp current $(I)$ by the open channel $I-V$ relationship, peaks around $-50 \mathrm{mV}$, so these channels appear maximally active in the normal resting potential range. Interestingly, the probability curve obtained for these paranodal channels overlaps closely with the steady-state open-channel probability (Fig. 7, smooth curve) reported for inward rectifiers seen in the newborn Schwann cell soma in identical recording solutions (Wilson and Chiu, 1990). Both curves appear to decrease as the potential approaches 0 . However, whether the probability actually goes to 0 around $0 \mathrm{mV}$ is difficult to assess due to uncertainties in resolving small currents. 
A
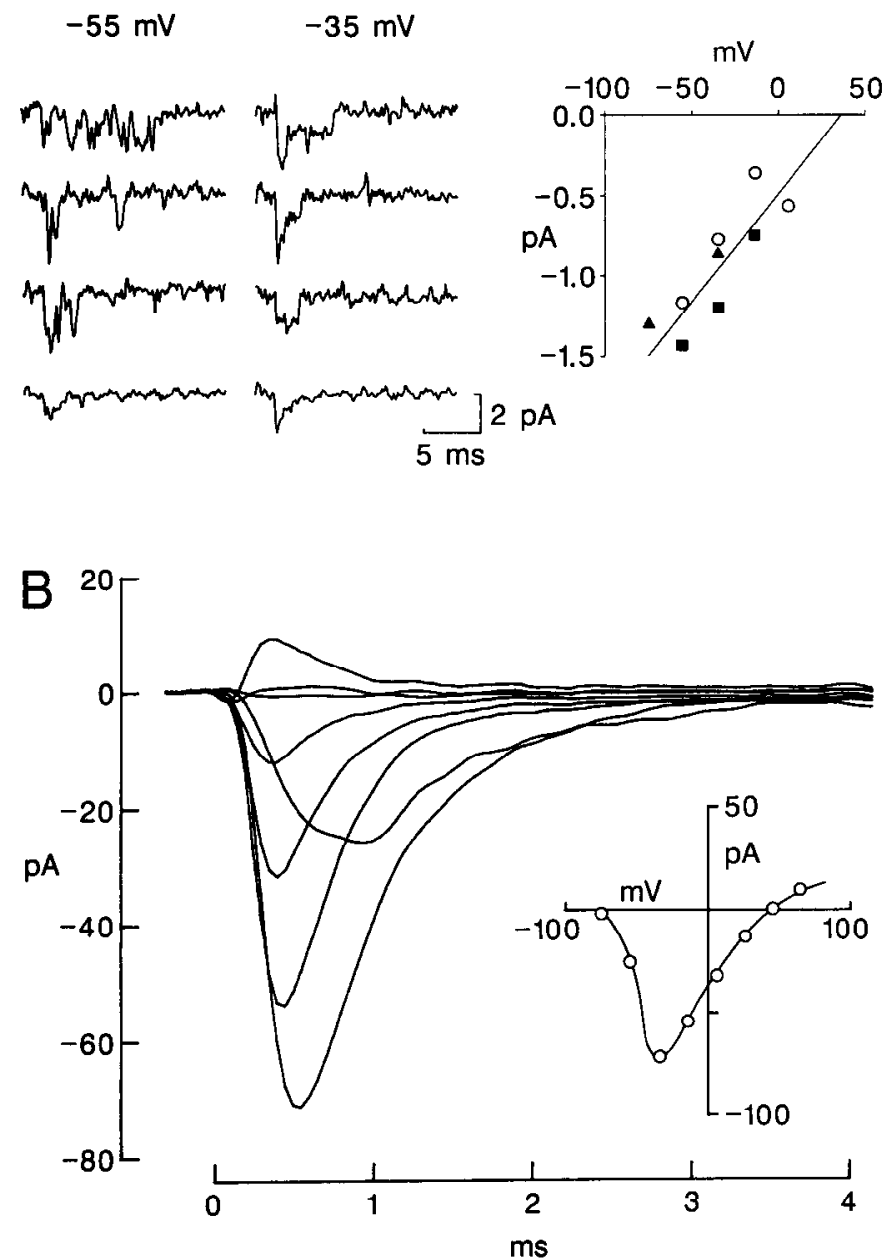
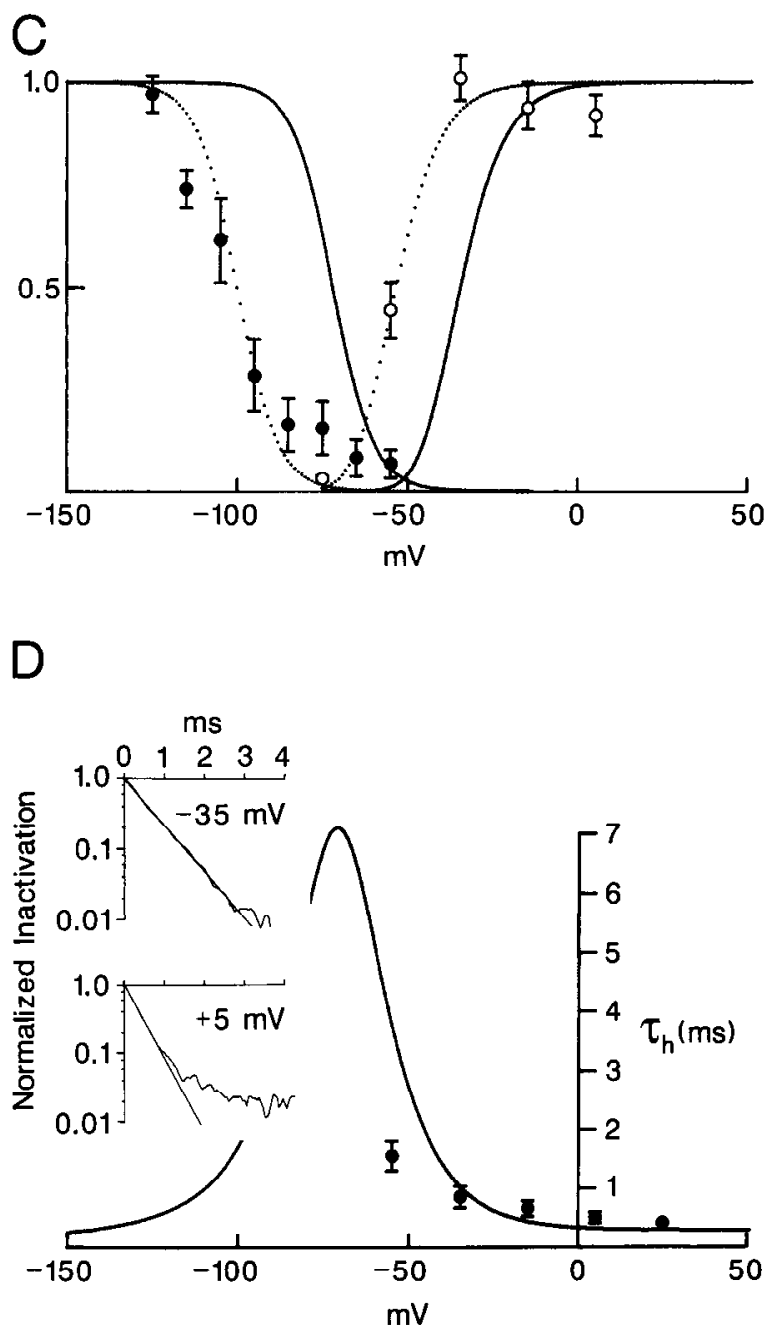

Figure 8. Sodium currents in outside-out patches of axon-derived paranodal membrane. $A$, Single-channel sodium currents. The top 3 traces in the left columns are individual responses, and the bottom traces are the corresponding ensemble average of 10 traces. The patch was stepped to the indicated test potentials from a $100-\mathrm{msec}$ prepulse to $-120 \mathrm{mV}$. The single-channel $I-V$ relationship is shown on the right $(n=3)$; the straight line represents a least-square fit to the data with a single-channel conductance of $13 \mathrm{pS}$. $B$, Ensemble sodium currents observed in a separate patch that has a much larger amplitude than $A$. The currents were generated by a family of step depolarizations ranging from -75 to $+65 \mathrm{mV}$ in 20 $\mathrm{mV}$ increments, preceded by a prepulse to $-120 \mathrm{mV}$. The corresponding peak $I-V$ relation is shown in the inset. $C$, Voltage dependence of sodium activation (open circles, $n=4$ ) and inactivation (solid circles, $n=3$ ). Normalized activation and inactivation of peak ensemble currents were determined as described in Materials and Methods. The 2 solid curves represent the theoretical activation and inactivation taken from Schwarz and Eikof (1987) for sodium currents in rat nodes. For steady-state $\mathrm{Na}$ inactivation, $\mathrm{h}_{\infty}$ was calculated according to the equation $\mathrm{h}_{\infty}=1 /(1+$ $\exp \left[\left(V-V_{h}\right) / k\right]$ ), with $V_{h}=-72 \mathrm{mV}$ and $k=6.02 \mathrm{mV}$ (from Fig. 7 of Schwarz and Eikhof, 1987; for comparison with our data, the potentials for the rat nodal data have been converted to absolute potentials using the reported resting potential of $-78 \mathrm{mV}$ in that study). For steady-state $\mathrm{Na}$ activation, the solid curve represents $\mathrm{m}_{\infty}{ }^{3}$, where $\mathrm{m}_{\infty}=1 /\left(1+\exp \left[\left(V_{m}-V\right) / k\right]\right)$, with $V_{m}=-45 \mathrm{mV}$ and $k=7.84 \mathrm{mV}$ (from Fig. 6 of Schwarz and Eikhof, 1987). The dotted curve represents the result of shifting the theoretical $\mathrm{h}_{\infty}$ and $\mathrm{m}_{\infty}{ }^{3}$ curves by -28 and $-19 \mathrm{mV}$, respectively. $D$, Voltage dependence of the timc constant of inactivation $\tau_{h}$ (solid circles, $n-5$ ). The insets show semilog plots of the sodium current decay, showing a single exponential phase at $-35 \mathrm{mV}$ and a biphasic one at $+5 \mathrm{mV}$; only the initial time constant is plotted, however. The solid curve is a theoretical curve from rat nodes calculated according to the equation $\tau_{h}=1 /\left[\alpha_{h}(V)+\beta_{h}(V)\right]$, with $\alpha_{h}(V)$ and $\beta_{h}(V)$ taken from Table 1 of Schwarz and Eikhof (1987). In all cases $(A-D)$, data were filtered at $2 \mathrm{kHz}$ and sampled every $100 \mu \mathrm{sec}$. The bath contained $156 \mathrm{mM} \mathrm{NaCl} L o c k e$ solution; pipettes contained $70 \mathrm{~mm} \mathrm{CsCl}$ and $70 \mathrm{~mm} \mathrm{TEACl}$.

\section{Sodium currents}

Sodium currents were isolated by using pipettes containing 70 $\mathrm{mM} \mathrm{CsCl}$ and $70 \mathrm{~mm}$ TEACl. Out of a total of 19 axon-derived patches studied under these conditions, 13 had detectable sodium currents. In contrast, sodium currents were not observed in any of the 9 patches that were clearly identified as myelin derived. As a result, the remaining data discussed originate from the axonal membrane. Even though sodium channels have not been detected in Schwann patches, we have included an analysis of axonal sodium channels because this is the first report of single-channel recordings at or near the mammalian node, and it would be of interest to see if single-channel properties conform to previous studies of mammalian channels using the macroscopic voltage clamp.

Figure $8 A$, left, shows currents obtained from an outside-out patch that contained 2-3 channels. The patch was stepped to the indicated potentials from a prepulse potential of $-120 \mathrm{mV}$; 
the top 3 traces are original individual responses, while the bottom trace is an ensemble average of 10 such traces. Channels opened rapidly after the onset of the voltage pulse, and the amplitude of single-channel currents decreased with increasing depolarization. Single-channel current amplitudes from 3 different patches are plotted against the test potential in the $I-V$ relationship shown on the right. The estimated single-channel conductance is $13 \mathrm{pS}$, similar to $11 \mathrm{pS}$ reported for the frog node by Jonas et al. (1989).

The observed magnitude of peak sodium currents varied a great deal from patch to patch, even for comparable pipette resistances $(R)$. The peak sodium current observed in the 13 axon-derived patches with currents ranged from -2 to -165 pA. In the outside-out patch shown in Figure $8 B(R=21 \mathrm{M} \Omega)$, the family of current responses was elicited by a series of voltage steps ranging from -55 to $+65 \mathrm{mV}$. Test pulses were preceded by a prepulse to $-120 \mathrm{mV}$ to remove resting inactivation. In this patch, the average magnitude of the peak sodium current was roughly 40 times the size of that presented in Figure $8 A(R$ $=20 \mathrm{M} \Omega$ ). This variability in current magnitude might be due to a variation in the original proximity of the membrane to the node. Despite the difference in response magnitudes, however, currents in the 2 patches behaved similarly. As shown in the inset $I-V$ relations (Fig. 8.4,B), the largest inward current was observed in response to the $-35-\mathrm{mV}$ test pulse, and currents reversed at $+45 \mathrm{mV}$, in agreement with the predicted Nerstian value of $+44 \mathrm{mV}$ (using an internal sodium concentration of $27 \mathrm{~mm}$; see Materials and Methods).

In Figure $8 C$, the average voltage dependence of activation (open circles; $N=4$ ) and inactivation (solid circles; $N=3$ ) are examined more closely. The time constant of inactivation, $\tau_{h}$, is shown in Figure $8 D$. Sodium current inactivation proceeds more or less in a single exponential fashion $(-35 \mathrm{mV}$; see inset in $D$ ); however, at higher depolarizations, a second slow phase of inactivation is apparent $(+5 \mathrm{mV}$; inset in $D)$. Biphasic decay of sodium current has been well described in gap-clamp studies of both amphibian and mammalian nodes (Chiu, 1977; Neumke and Stampfli, 1982). The solid curves give the theoretical relations for these parameters obtained from traditional gap-clamp experiments on rat nodes (Schwarz and Eikhof, 1987). In comparison with the theoretical curves, the respective data for the various parameters appear similar in shape but shifted in the hyperpolarizing direction. This shift is most likely due to the virtual absence of $\mathrm{Ca}^{2+}$ in our solutions. In frog nodes, solutions with no added calcium shift sodium current parameters by -18 $\mathrm{mV}$ relative to normal ( $2 \mathrm{~mm}$ ) calcium (Hille et al., 1975). Indeed, our data appcar wcll fit by the theorctical curves when they are shifted by $-28 \mathrm{mV}$ and $-19 \mathrm{mV}$ for inactivation and activation, respectively (Fig. $8 \mathrm{C}$, dotted lines).

\section{Discussion}

Axons in the CNS are surrounded by a variety of neurons, interneurons, and multiple glial cell types. Intuitively, in the PNS, the axon at its isolated outpost would seem to rely more heavily on its immediate environment for integration or modulation of incoming signals, buffering of ions, and general metabolic support. As a result, it seems surprising that voltagegated ion channels have been demonstrated on every glial cell type except the mature myelinating Schwann cell. The present study indicates that, in fact, ion channels are present in adult myelinating Schwann cells, and furthermore, that the channels observed are positioned optimally for a functional interaction with axons and, thus, for a maximum impact on saltatory conduction. Specifically, the average current per patch measured at the soma at day 45 is 0.05 and $0 \mathrm{pA}$ for delayed and inward rectifiers ( $n=55$, see fig. 7 of Wilson and Chiu, 1990); in comparison, the corresponding average current per paranodal patch for the delayed rectifier measured under similar conditions is at least 40 -fold higher.

Recent studies on frog myelinated nerves (Jonas et al., 1989) have suggested that it is possible to record directly from axonal channels using patch clamp on retracted paranodes similar to those of the present study. Their results suggest that at least 3 kinetically distinct potassium-channel subtypes underlie the observed axonal macroscopic current. While a detailed kinetic analysis of single-channel properties was not possible in the present study due to the large number of channels present in most patches (as well as the difficulties inherent in Lucifer injections), delayed rectifying potassium channels in both the frog and the rat begin to activate over a similar voltage range ( -60 to $-50 \mathrm{mV}$ ). In addition, because the currents observed in both axon- and Schwann-derived patches are fully activated within $25 \mathrm{mV}$, they appear most similar to those of the axonal I-type potassium channel. The other potassium channel type $(F)$ whose activation is described by Jonas et al. (1989) activated over a much broader voltage range. Obviously, however, because our analysis is based primarily on macroscopic currents, contributions of the other potassium channels to the overall current cannot be ruled out and, indeed, seem likely.

In the present study of mammalian nerves, there appear to be no morphological characteristics, at least at the light microscopic level, that allow a reliable distinction between axon and Schwann membrancs at retractcd paranodes. For cxample, Lucifer yellow injections at both straight (Fig. $2 A$ ) and tapered (Fig. $2 B$ ) retracted paranodes could mark Schwann cells. Even though Lucifer staining seems the most reliable way to identify membranes in patch-clamp studies on retracted mammalian paranodes, a more convenient criterion, at least for axonal membranes, is the presence of regenerative sodium currents in whole-cell recordings. Indeed, such regenerative sodium currents were frequently seen in whole-cell recordings during Lucifer injection. In all of these cases, the dye was subsequently found to be restricted to axons. In contrast, because large sodium currents were not a characteristic of all axon stains, there appears to be no clear way of identifying Schwann-derived patches without recourse to Lucifer staining.

\section{Comparison of glial and axonal currents}

Sodium currents. When comparing axon- and Schwann-derived patches, a major difference in excitability is the apparent absence of sodium channels in patches originating from Schwann cell membranes. However, given the small number of successful patches achieved in sodium current isolation solutions, the conclusion that sodium channels are absent from Schwann cell paranodal processes seems premature. Sodium channels may be localized to inaccessible areas, or channel density may be low. In fact, inward currents resembling sodium currents were detected in 1 patch where Lucifer staining was questionable; that is, dye stayed on 1 side of the node but was dim and did not appear to extend completely to the outer myelin perimeter. Because this staining pattern could have been due either to incomplete diffusion of Lucifer yellow through the myelin or to collapse of the axon, we felt it was not justified to categorize the patch as myelin derived. 
Potassium currents. Analysis of macroscopic currents suggests that the potassium channels observed in axon- and Schwannderived patches behave similarly. Apart from the apparent difference in current magnitudes, the only difference in potassium currents would appear to be in their activation thresholds. The currents observed in Schwann-derived patches activated at potentials approximately $15 \mathrm{mV}$ negative to current activation in axons.

\section{Functions of paranodal Schwann cell ion channels}

While recent studies suggest a variety of roles for glial ion channels, 2 appear particularly relevant when considering channels localized within the paranodal apparatus: local transfer of channels to the axon and buffering or accumulation of extracellular potassium ions released during nerve activity. The implications of the present results for both of these hypothesized roles are considered below.

Glial-to-axon transfer of ion channels. An intriguing aspect of studies on glial ion channels is the diversity of channel types and the at least qualitative similarity betwecn glial and neuronal channel populations. The apparent duplication of ion channel populations in glia and axons has led to the suggestion that glia provide a local source of channels for axons and, thus, complement neuronal synthesis and axonal transport (Gray and Ritchie, 1985). Channels might be transferred to axons via the Schwann cells' paranodal microvilli. In this regard, the present study was unable to convincingly locate sodium channels in Schwann-derived paranodal patches. As discussed above, however, there are several plausible reasons for the apparent absence of sodium currents, including the possibility that sodium channels may be highly localized to a region not accessible to our patch pipettes even in retracted paranodes. Indeed, an antibody to sodium channels has been found to label the cytoplasm and plasmalemma of perinodal astrocytes and Schwann cell processes (Black et al., 1989, 1990). However, it is not clear that this labeling corresponds to functional sodium channels, though obviously channels need not be operative in the Schwann cell membranes for channel transfer to occur.

Buffering or accumulation of extracellular potassium. To date, most evidence suggests that inwardly rectifying potassium channels, as opposed to pumps or active transport processes, are involved in glial regulation of extracellular potassium (Barres et al., 1990). However, both the delayed rectifying potassium channels (which activate close to $-75 \mathrm{mV}$ in Fig. 5, though the actual value may be up to $20 \mathrm{mV}$ more depolarized because of the low-calcium solution used) and inwardly rectifying potassium channels found in Schwann-derived patches appear well suited for extracellular potassium regulation. The inwardly rectifying channel is maximally open in the region of the resting potential (Fig. 7) and therefore would appear to be the first channel recruited should local potassium concentrations increase. Delayed rectifying channels, on the other hand, would appear to activate according to demand. Local increases in extracellular potassium should both activate delayed rectifiers according to the degree of depolarization and shift the potassium equilibrium potential so that these channels would carry inward current, at least for potassium increases in the physiological range.

Primarily 2 homeostatic mechanisms are currently undcr consideration. In the first mechanism, referred to as spatial buffering (Orkand et al., 1966; Newman, 1984, 1985), local potassium increases are shunted to spatially removed areas. In the second mechanism, referred to as potassium accumulation (Boyle and Conway, 1941; Barres et al., 1988, 1990), potassium entering glia via ion channels is balanced by the entry of chloride and water and, as a result, can be stored locally within glia for later release. Although potassium accumulation mechanisms appeared favored in most CNS glia (Barres et al., 1990), at present it seems difficult to similarly conclude the accumulation mechanism is operative in Schwann cells. While chloride channels have been observed in cultures of newborn rat Schwann cells (Howe and Ritchie, 1988), their presence has yet to be demonstrated in adult myelinating Schwann cells. One might hypothesize that these chloride channels should be colocalized with potassium channels in the paranodal processes. Until such channels are found, it is difficult to consider accumulation as the primary homeostatic mechanism in force in Schwann cells.

Finally, it is important to note that spatial buffering mechanisms rely on an additional potassium conductance for potassium efflux that is located some distance away from the site of influx. The path for efflux could include either a leakage or a voltage-gated potassium conductance and should be present in cither the soma or the myelin sheath. As mentioned earlier, under most conditions, voltage-gated ionic currents are not detectable in recordings made at the soma of adult myelinating Schwann cells. However, while the present study offers evidence that channels are present in Schwann cell paranodal processes, it does not address whether channels might also be present along the myelin sheath.

Diffusion in the nodal gap. The node of Ranvier presents a special case for ionic buffering due to its unique morphological, electrophysiological, and cytochemical properties. A large body of evidence indicates that ions may not diffuse freely in the nodal gap. The nodal membrane is located at the bottom of a gap whose walls are particularly "high" and are formed by the outer paranodal Schwann cell membrane. Further, the Schwann cell apparatus bulges out so that the top of the gap is narrower than the bottom. Effectively, these Schwann cell collars can be thought of as a "lid" partially isolating the nodal microenvironment from the bulk extracellular space. In large-diameter fibers, the remaining nodal gap is densely packed by $800-1000$ small Schwann cell microvilli, and the space between them is filled by a matrix substance that exhibits strong cation binding properties (Landon and Langley, 1971). Indeed, in the nodal gap, electrophysiological studies have estimated that $\mathrm{K}$ ions diffuse only $1 / 10$ as fast as in free diffusion (Moran et al., 1980), and there is a large accumulation of $\mathrm{K}^{+}$during ionic efflux produced by a maintained depolarization (Dubois and Bergman, 1975; Moran et al., 1980).

The cytochemical properties of the gap substance itself have been proposed to regulate the ionic microenvironment during excitation. For example, its cationic binding properties may act to concentrate $\mathrm{Na}^{+}$in the nodal vicinity, hence serving as a reservoir for the $\mathrm{Na}^{+}$needed during saltatory conduction; likewise, $\mathrm{K}^{+}$leaving the nodal membrane may be temporarily held by the gap substance and handed back to the node during recovery from an action potential (Landon and Langley, 1971).

In addition to cation binding and diffusion mechanisms, the $\mathrm{K}$ channels present on Schwann cell membranes may increase the efficiency of buffering of free $\mathrm{K}^{+}$in the nodal gap region. The numerous Schwann cell microvilli represent a dramatic increase in the ratio of surfacc arca to volume, a characteristic typical of an absorptive system. The total membrane area of the microvilli is about 13 times that of the nodal membrane (Berthold and Rydmark, 1983a, b). This means that even if the Schwann K-channel density is about 10 times smaller than for 
axons, the system of microvilli as a whole offers the same $K$ conductance as in adjacent axonal membrane. In this regard, myelin splitting and paranodal vacuolization have been observed following prolonged nerve stimulation (Moran and Mateu, 1983; Wurtz and Ellisman, 1986). This may indicate massive entrance of $\mathrm{K}^{+}$into Schwann cells, which, with the accompanying influx of water to maintain osmotic balance, may cause Schwann cell swelling.

At present, it is unclear whether buffering of $\mathrm{K}^{+}$by paranodal Schwann cell membranes has a physiological role in normal conduction. For instance, bath application of 3-5 $\mathrm{mM} \mathrm{Cs}^{+} \mathrm{did}$ not impair the frequency of firing in rat spinal root myelinated axons during tetanus, but did lead to a change in the threshold for excitation (Baker et al., 1987). It is possible this change in axonal excitability resulted from a disruption of the glial buffering offered by Schwann cell inward rectifiers that are blocked by $\mathrm{Cs}^{+}$(Wilson and Chiu, 1990). It should be noted, however, that the effect of global disruption of glial buffering may not have been seen, because Schwann cell delayed rectifiers are not affected by low concentrations of externally applied $\mathrm{Cs}^{+}$(Wilson and Chiu, 1990). In addition, the paranodal, and possibly internodal, inward rectifier population may have been only partially affected, because $\mathrm{Cs}^{+}$was applied for less than $5 \mathrm{~min}$ in the studies of Baker et al. (1987), and Schwann cell inward rectifiers may be partially concealed by myelin (Fig. 1). Finally, both theoretical calculations (Chiu and Ritchie, 1984) and experimental studies (Barrett and Barrett, 1982) show that the internodal membrane can be coupled electrotonically to the nodal membrane in intact myelinated nerves. Whether internodal $\mathrm{K}$ channels (Chiu and Ritchie, 1980; Roper and Schwarz, 1989) could contribute to $\mathrm{K}^{+}$accumulation in periaxonal space and whether these ions are cleared by channels located in the innermost Schwann cell turn remain open questions.

\section{Regulation of ion channel expression}

In previous studics, wholc-cell recordings at the soma of myclinating Schwann cells have shown that voltage-gated currents are not detectable in adults, suggesting that these soma lack channels. Indeed, as measured by cell-attached recordings, potassium channels present on the soma of newborn myelinating Schwann cells are rapidly down-regulated during the first week after birth as cells begin to elaborate myelin and are virtually absent from the soma by day 45 (Wilson and Chiu, 1990). During development, once myelin is formed, channels may migrate from the cell soma to the myelin sheath and distant paranodal processes. Alternatively, somal and paranodal channels might be under separate regulatory control. In either case, channels may require a local axonal signal to remain anchored in the Schwann cell membrane. Indeed, axonal contact appears important both to the regulation of Schwann cell proliferation (Wood and Bunge, 1975) and the determination of cell phenotype (Aguayo et al., 1976). Therefore, the simplest mechanism that would account for a nonuniform distribution of channels in myelinating Schwann cells would appear to rely, in part, on a cell-cell trophic interaction, the effect of which depends on distance of the Schwann cell membrane from the axon. This distance is shortest at birth, when the soma of myelinating Schwann cells are in close contact with axonal membranes, but becomes longer as myelin is elaborated. A distance-related mechanism also would serve to account for the observed differential distribution of channels in the soma of adult nonmyelinating and myelinating Schwann cells (Chiu, 1987, 1988).

Why might the channels on myelinating cells be nonuniformly distributed? A particularly appealing suggestion is that somal and paranodal channels subserve different functions. Channels located on the somas of myelinating Schwann cells appear to be involved in self-supporting functions such as proliferation and myelination, as suggested in recent reports (Wilson and Chiu, 1988; Chiu and Wilson, 1989), whereas channels present at paranodal processes would seem to be more relevant to local axonal needs, such as protein transfer (Lasek and Tytell, 1981) or maintenance of the nodal microenvironment supporting nerve transmission.

\section{References}

Aguayo AJ, Charron L, Bray GM (1976) Potential of Schwann cells from unmyelinated nerves to produce myelin: a quantitative ultrastructural and radiographic study. J Neurocytol 5:565-573.

Baker M, Bostock H, Grafe P, Martius P (1987) Function and distribution of three types of rectifying channel in rat spinal root myelinated axons. J Physiol (Lond) 383:45-67.

Barres BA, Chun LLY, Corey DP (1988) Ion channel expression by white matter glia. I. Type 2 astrocytes and oligodendrocytes. Glia 1: $10-30$.

Barres BA, Chun LLY, Corey DP (1990) Ion channels in vertebrate glia. Annu Rev Neurosci 13:441-474.

Barrett EF, Barrett JN (1982) Intracellular recording from vertebrate myelinated axons: mechanism of the depolarizing afterpotential. J Physiol (Lond) 323:117-144.

Berthold C-H, Rydmark M (1983a) Anatomy of the paranode-nodeparanode region in the cat. Experientia 39:964-976.

Berthold C-H, Rydmark M (1983b) Electron microscopic serial section analysis of nodes of Ranvier in lumbosacral spinal roots of the cat: ultrastructural organization of nodal compartments in fibres of different sizes. J Neurocytol 12:475-505.

Black JA, Waxman SG, Friedman B, Elmer LW, Angelides KJ (1989) Sodium channels in astrocytes of rat optic nerve in situ: immunoelectron microscopic studies. Glia 2:353-369.

Black, JA, Friedman B, Cornell-Bell A, Angelides KJ, Ritchie JM, Waxman SG (1990) Immuno-localization of sodium channels in axon membrane and astrocytes and Schwann cells in vivo and in vitro. In: Cellular and molecular biology of myelination (Althaus $\mathbf{H}$, Jeserich G, Waehneldt T, eds). Berlin: Springer, in press.

Blank WF Jr, Bunge MB, Bunge RP (1974) The sensitivity of the myelin sheath, particularly the Schwann cell-axolemmal junction, to lowered calcium levels in cultured sensory ganglia. Brain Res 67:503518.

Boyle, PJ, Conway EJ (1941) Potassium accumulation in muscle and associated changes. J Physiol (Lond) 100:1-63.

Brismar T (1983) Nodal function of pathological nerve fibers. Experientia 39:946-953.

Chiu SY (1977) Inactivation of sodium channels: second order kinetics in myelinated nerve. J Physiol (Lond) 273:573-596.

Chiu SY (1987) Sodium currents in axon-associated Schwann cells from adult rabbits. J Physiol (Lond) 386:181-203.

Chiu SY (1988) Changes in excitable membrane properties in Schwann cells of adult rabbit sciatic nerves following nerve transection. J Physiol (Lond) 396:173-188.

Chiu SY, Ritchie JM (1980) Potassium channels in nodal and internodal axonal membrane of mammalian myelinated fibre. Nature 284 : 170-171.

Chiu SY, Ritchie JM (1984) On the physiological role of internodal potassium channels and security of conduction in myelinated nerve fibres. Proc R Soc Lond [Biol] 220:415-422.

Chiu SY, Wilson GF (1989) The role of potassium channels in Schwann cell proliferation in Wallerian degeneration of explant rabbit sciatic nerves. J Physiol (Lond) 408:199-222.

Conti F, Hille B, Nonner W (1984) Nonstationary fluctuations of the potassium conductance at the node of Ranvier in the frog. J Physiol (Lond) 353:199-230.

Dubois JM, Bergman C (1975) Potassium accumulation in the perinodal space of frog myelinated axons. Pfluegers Arch 358:111-124.

Ellisman MH, Friedman PL, Hamilton WJ (1980) The localization of sodium and calcium to Schwann cell paranodal loops at nodes of Ranvier and of calcium to compact myelin. J Neurocytol 9:185-205.

Gray PTA, Ritchie JM (1985) Ion channels in Schwann and glial cells. Trends Neurosi 8:411-415. 
Hamill OP, Marty A, Neher E, Sakmann B, Sigworth F (1981) Improved patch-clamp techniques for high-resolution current recording from cells and cell-free membrane patches. Pfluegers Arch 391:85100.

Hille B, Woodhull AM, Shapiro BI (1975) Negative surface charge near sodium channels of nerve: divalent ions, monovalent ions, and pH. Phil Trans R Soc Lond [Biol] 270:301-318.

Howe JR, Ritchie JM (1988) Two types of potassium current in rabbit cultured Schwann cells. Proc R Soc Lond [Biol] 235:19-27.

Jonas P, Brau ME, Hermsteiner M, Vogel W (1989) Single-channel rccording in myclinated nerve fibers reveals one type of $\mathrm{Na}$ channel but different $K$ channels. Proc Natl Acad Sci USA 86:7238-7242.

Landon DN, Langley OK (1971) The local chemical environment of nodes of Ranvier: a study of cation binding. J Anat 108:419-432.

Lasek RJ, Tytell MA (1981) Macromolecular transfer from glia to axon. J Exp Biol 95:153-165.

Moran O, Mateu L (1983) Loosening of paranodal myelin by repetitive propagation of action potentials. Nature 304:344-345.

Moran N, Palti Y, Levitan E, Stampfli R (1980) Potassium ion accumulation at the external surface of the nodal membrane in frog myelinated fibers. Biophys J 32:939-954.

Neumcke B, Stampfli R (1982) Sodium currents and sodium current fluctuations in rat myelinated nerve fibres. J Physiol (Lond) 329:163184.

Ncwman EA (1984) Regional specialization of retinal glial cell membrane. Nature 309:155-157.

Newman EA (1985) Voltage-dependent calcium and potassium channels in retinal glial cells. Nature 317:809-811.
Orkland RK, Nichols JG, Kuffler SW (1966) Effect of nerve'impulses on the membrane potential of glial cells in the central nervous system of amphibia. J Neurophys 29:788-806.

Ranscht B, Clapshaw PA, Price J, Noble M, Seifert W (1982) Development of oligodendrocytes and Schwann cells studied with a monoclonal antibody against galactocerebroside. Proc Natl Acad Sci USA 79:2709-2713.

Roper J, Schwarz JR (1989) Heterogeneous distribution of fast and slow potassium channels in myelinated rat nerve fibers. J Physiol (Lond) 416:93-110.

Schwarz JR, Eikhof G (1987) Na currents and action potentials in rat myelinated nerve fibres at 20 and $37^{\circ} \mathrm{C}$. Pfluegers Arch 409:569-577.

Shrager P, Chiu SY, Ritchie JM (1985) Voltage-dependent sodium and potassium channels in mammalian cultured Schwann cells. Proc Natl Acad Sci USA 82:948-952.

Stampfli R, Hille B (1976) Electrophysiology of the peripheral myelinated nerve. In: Frog neurobiology (Llinas R, Precht W, eds), pp 132. Berlin: Springer.

Wilson GF, Chiu SY (1988) Effects of mitogens on Schwann cell ion channels. Soc Neurosci Abstr 14:64.

Wilson GF, Chiu SY (1990) Potassium channel regulation in Schwann cells during early developmental myelinogenesis. J Neurosci 10:16151625.

Wood PM, Bunge RP (1975) Evidence that sensory axons are mitogenic for Schwann cells. Nature 256:662-664.

Wurtz CC, Ellisman MH (1986) Alterations in the ultrastructure of peripheral nodes of Ranvier associated with repetitive action potential propagation. J Neurosci 6:3133-3143. 